УДК 547.793

DOI https://doi.org/10.32838/2663-5941/2020.1-2/15

Сімурова Н.В.

Національний університет харчових технологій

\title{
Попова I.B.
}

Національний університет харчових технологій

\section{Майборода O.I.}

Національний університет харчових технологій

Кармашов О.О.

Національний університет харчових технологій

\section{ЗРУЧНИЙ МЕТОД ОДЕРЖАННЯ 2-АРИЛ(ГЕТЕРИЛ)-5-ХЛОРМЕТИЛ-1,3,4-ОКСАДІАЗОЛІВ}

Молекула 1,3,4-оксадіазолу викликає значний інтерес завдяки широкому спектру біологічної та фармакологічної активності. Вона широко представлена в якості привілейованої структури в хімії лікарських речовин. Тому розробка зручних методів одержсання заміщених 1,3,4-оксадіазолів є актуальним напрямом досліджень. Особливо иіккавими є похідні 1,3,4-оксадіазолів, які містять реакційноздатне хлорметильне угруповання, що дозволяе їх подальщу хімічну модифікаиію.

Робота присвячена розробиі зручного препаративного способу одержсання 2-арил(гетерил)5-хлорметил-1,3,4-оксадіазолів. Запропоновано схему, в якій вихідними речовинами є комерційно доступні ароматичні та гетерочиклічні карбонові кислоти. Метод трунтується на одержсанні гідразидів карбонових кислот, їх подальшому ацилуванні та ичклізаиії синтезованих проміжних продуктів під дією трихлороксиду фосфору (V). Перевагами методу є високі виходи иџільових 1,3,4-оксадіазолів і відсутність необхідності очищати проміжні сполуки, що значно спрощуе процедуру, скорочуе необхідний час, економить реагенти. Метод придатний як для одержання широкого кола 2-арил-5-хлорметил-1,3,4-оксадіазолів, так і деяких похідних із гетерочиклічними замісниками, зокрема з фурильним або тієнільним.

Будову всіх отриманих сполук підтверджено спектрами ЯМР ${ }^{l} H$, а їх склад - елементним аналізом. Результати проведених досліджень можуть бути застосовані у синтетичній практиці, а одержані сполуки, що містять реакційноздатну хлорметильну групу, є перспективними білдинг-блоками для їх подальшої хімічної модифікації з метою одержання біологічно активних похідних, які можуть знайти застосування в якості лікарських засобів, інсектицидів тощо.

Ключові слова: синтез, ичиклізація, гідразид, хлорацетилхлорид, 1,3,4-оксадіазол, хлороксид фосфору.

Постановка проблеми. Оксадіазоли існують у чотирьох ізомерних формах, проте саме похідні 1,3,4-оксадіазолу мають широкий спектр біологічної активності. Серед них знайдені сполуки з противірусною, протипухлинною, антимікробною, аналгетичною, інсектицидною властивостями. На сьогоднішній день препарати 3 оксадіазольним циклом застосовуються у практичній медицині в якості антиретровірусних і протипухлинних препаратів $[1 ; 2]$. Цей гетероциклічний фрагмент у медичній хімії розглядається як біоізостер карбонових кислот, естерів та амідів, для якого характерне різноманіття властивостей і застосувань [3].

Згідно літературних даних, дослідження функціональних похідних 1,3,4-оксадіазолів зосереджено як на пошуку нових методів синтезу сполук цієї групи, так і на пошуку нових галузей їх застосування. Значний обсяг наукових джерел свідчить про потенціал таких досліджень, тому розробка зручних методів одержання цих речовин $\epsilon$ актуальною.

Аналіз останніх досліджень і публікацій. У науковій літературі останніх років $є$ значна кількість повідомлень щодо синтезу, дослідження властивостей і можливостей практичного застосування речовин із 1,3,4-оксадіазольним циклом. Цій темі присвячено декілька грунтовних оглядів [4; 5]. Зокрема, показано можливість застосування сполук цього класу в якості лікарських препаратів, інсектицидів. Значна кількість робіт присвячена дизайну та синтезу нових похідних із 1,3,4-оксадіазольним циклом. 
Сучасні тенденції одержання 1,3,4-оскадіазолів грунтуються на реакціях окисної циклізації, застосуванні дегідратуючих агентів [6; 7], пошуку нових мультикомпонентних реакцій, реакцій рециклізації [8]. Проведений аналіз досліджень у цій галузі показав актуальність пошуку зручних підходів до синтезу нових функціоналізованих похідних 1,3,4-оксадіазолів, які містять реакційноздатне хлорметильне угруповання та ароматичний або гетероциклічний фрагмент. У перспективі це дозволить знайти нові речовини з високою біологічною активністю для потреб як фармацевтичної, так і інших галузей хімічної промисловості. Ця робота є продовженням досліджень авторів, присвячених методам одержання дизаміщених 1,3,4-оксадіазолів [9].

Мета статті. Метою роботи був пошук оптимальної схеми синтезу 2-арил(гетерил)5-хлорметил-1,3,4-оксадіазолів, яка давала б можливість одержувати препаративні кількості цільових речовин із високими виходами. Цільові сполуки є перспективними щодо подальшої функціоналізації та вивчення біологічного потенціалу їх похідних. Особливу увагу приділено комерційній доступності вихідних речовин і можливості регенерації застосованих розчинників, що дозволяє значно економити необхідні реагенти.

Виклад основного матеріалу дослідження. Вякостівихіднихсполукдлясинтезу2-арил(гетерил)5-хлорметил-1,3,4-оксадіазолів було обрано ряд комерційно доступних ароматичних і гетероциклічних карбонових кислот. Ключовими інтермедіатами в синтезі заміщених 1,3,4-оксадіазолів є гідразиди карбонових кислот. Для їх одержання авторами були синтезовані бутилові естери відповідних кислот 2 , які оброблялися 65\%-м розчином гідразин-гідрату. Наступною стадією було ацилування гідразидів 3 за допомогою хлорацетилхлориду з подальшою циклізацією ацильованих продуктів 4 у цільові 5-арил2-хлорметил-1,3,4-оксадіазоли 5, що представлено у хімічній схемі:

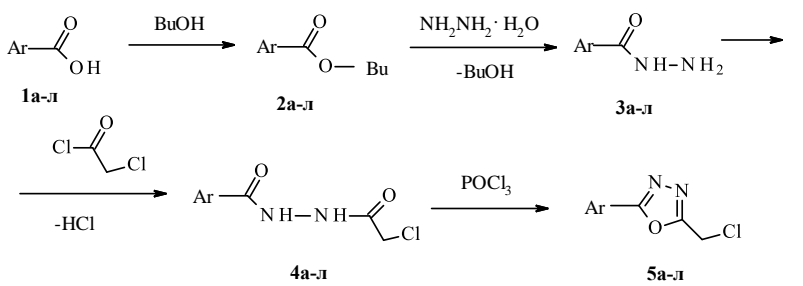

1-5a $\mathrm{Ar}=\mathrm{C}_{6} \mathrm{H}_{5} ; \mathbf{1 - 5}$ б $\mathrm{Ar}=4-\mathrm{CH}_{3}-\mathrm{C}_{6} \mathrm{H}_{4} ; \mathbf{1 - 5} \mathbf{B}$ $\mathrm{Ar}=4-\mathrm{CH}_{3} \mathrm{OC}_{6} \mathrm{H}_{4} ; \mathbf{1 - 5} \Gamma \mathrm{Ar}=4-\mathrm{Cl}-\mathrm{C}_{6} \mathrm{H}_{4} ;$

1-5 $\mathrm{Ar}=4-\mathrm{F}-\mathrm{C}_{6} \mathrm{H}_{4} ; 1-5 \mathrm{e} \mathrm{Ar}=4-\mathrm{Br}-\mathrm{C}_{6} \mathrm{H}_{4} ; \mathbf{1 - 5 e}$ $\mathrm{Ar}=4-\mathrm{NO}_{2}-\mathrm{C}_{6} \mathrm{H}_{4} ; \mathbf{1 - 5} \% \mathrm{Ar}=2,4-\mathrm{Cl}_{2} \mathrm{C}_{6} \mathrm{H}_{3}$;

1-53 $\mathrm{Ar}=3,4-\mathrm{Cl}_{2} \mathrm{C}_{6} \mathrm{H}_{3} ; \mathbf{1 - 5 i} \mathrm{Ar}=2-\mathrm{Br}_{-} \mathrm{C}_{6} \mathrm{H}_{4} ; \mathbf{1 - 5} \mathbf{\kappa}$ $\mathrm{Ar}=3-\mathrm{CH}_{3} \mathrm{OC}_{6} \mathrm{H}_{4 ;} \mathbf{1}-\mathbf{5} \kappa \mathrm{Ar}=3,4\left(\mathrm{CH}_{3}\right)_{2} \mathrm{C}_{6} \mathrm{H}_{3}$.
Синтез гідразидів кислот за цією схемою $€$ зручним, оскільки гідразиди 3а-л $є$ нерозчинними у воді та легко відділяються фільтруванням. Їх аналіз свідчить про достатню чистоту (95-97\% за даними ЯМР-спектроскопії), тому подальші реакції проводили без додаткового очищення сполук 3. Використання бутанолу надає значні переваги, оскільки перебіг реакції зручно контролювати за кількістю утвореної води. Взаємодію сполук 3а-л iз хлорацетилхлоридом проводили при кип'ятінні реагентів у толуені, що приводило до ацильованих похідних 4а-л, які після охолодження реакційної суміші випадали в осад та відділялися фільтруванням. Як бутанол, так і толуен після реакції регенерували та застосовували багатократно.

У випадку фуран- та тіофенкарбонових кислот більш зручним виявилося застосування метилових естерів. Подальша схема їх синтезу не відрізняється від наведеної вище (сполуки 5м та 5н).

На перебіг реакцій впливають замісники у бензеновому ядрі: вихід цільових продуктів більший у речовин, які мають електроноакцепторні замісники в ароматичному ядрі. У випадку електронодонорних замісників $\left(\mathrm{CH}_{3}, \mathrm{OCH}_{3}\right)$ реакції відбуваються повільніше, потребуючи більш тривалого нагрівання. Виходи у таких випадках дещо нижчі.

Цільові сполуки є кристалічними речовинами, стійкими до звичайних умов зберігання. За наявності кислот і вологи вони повільно розкладаються 3 утворенням речовин 4, що свідчить про деяку ацидофобність оксадіазольних циклів. Характеристики сполук 5а-н наведено в таблиці 1.

Спектри ЯМР ${ }^{1} \mathrm{H}$ речовин були зареєстровані в розчині ДМСО-d 6 на приладі "Varian VXR-300", робоча частота - 300 МГц, внутрішній стандарт TMC. Контроль чистоти проводили за допомогою хромато-мас спектрометрії на приладі Agilent 1100 LC/MSD SL.

Загальнаметодикасинтезугідразидів 2-арил-5хлорметил-1, 3, 4-оксадіазолів 3а-л. До 0.2 моль карбонової кислоти 1а-л дослідники додавали 200 мл бутанолу та толуенсульфохлорид (5\% від маси кислоти) в якості каталізатора. Суміш кип'ятили у колбі з насадкою Діна-Старка до припинення утворення води (2-5 годин). Після охолодження реакційної суміші додавали 0,3 моль гідразингідрату (з концентрацією 65\%), після чого ії нагрівали до кипіння протягом 3 годин. Реакційну суміш залишали для охолодження до кімнатної температури, після чого осад, який утворювався, відфільтровували, промивали холодною водою та висушували за $60^{\circ} \mathrm{C}$ до постійної маси. Контроль чистоти проводили за допомогою хромато-мас спектрометрії, в подальшому застосовували без додаткового очищення. Виходи складали $85-100 \%$.

Загальнаметодикаачилюваннягідразидів 2-арил5-хлорметил 1,3,4-оксадіазолівхлорачетилхлоридом. 
Характеристика 2-арил(гетерил)-5-хлорметил-1,3,4-оксадіазолів

\begin{tabular}{|c|c|c|c|c|c|c|}
\hline \multirow{2}{*}{$\begin{array}{c}\text { № } \\
\text { сполуки }\end{array}$} & \multirow[b]{2}{*}{ Брутто-формула } & \multirow{2}{*}{$\begin{array}{c}\text { T. пл., } \\
\text { знайдена / } \\
\text { літ., }{ }^{\circ} \mathrm{C} \\
\end{array}$} & \multirow{2}{*}{$\begin{array}{c}\text { Дані ЯМР }{ }^{1} \text { Н спек- } \\
\text { троскопії, м. ч. }\end{array}$} & \multicolumn{2}{|c|}{ Дані елементного аналізу, \% } & \multirow{2}{*}{$\begin{array}{c}\text { Вихід *, } \\
\text { \% }\end{array}$} \\
\hline & & & & Знайдено & Розраховано & \\
\hline $5 \mathbf{a}$ & $\mathrm{C}_{9} \mathrm{H}_{7} \mathrm{ClN}_{2} \mathrm{O}$ & $\begin{array}{c}118-120 / 119- \\
121[10]\end{array}$ & $\begin{array}{c}4.80 \text { с., } 2 \mathrm{H} \\
7.5-7.6 \text { м. } 3 \mathrm{H}, 8.0-8.12 \\
\text { м. } 2 \mathrm{H} \\
\end{array}$ & $\begin{array}{c}\text { C } 55,50 \\
\text { H } 3,63 \\
\text { Cl } 18,19 \\
\text { N } 14,50 \\
\end{array}$ & $\begin{array}{l}\text { C } 55,54 \\
\text { H } 3,67 \\
\text { Cl } 18,22 \\
\text { N } 14,40 \\
\end{array}$ & 69 \\
\hline 5 б & $\mathrm{C}_{10} \mathrm{H}_{9} \mathrm{ClN}_{2} \mathrm{O}$ & $\begin{array}{c}117-120 / 117- \\
119[10]\end{array}$ & $\begin{array}{c}2.45 \text { с., } 3 \mathrm{H} \\
4.76 \text { с., } 2 \mathrm{H} \\
7.35 \text { д, } 2 \mathrm{H}, 7.95 \text { д. } 2 \mathrm{H}, \\
\mathrm{J}_{\mathrm{HН}}=8 \text { Гц }\end{array}$ & $\begin{array}{c}\text { C } 59,28 \\
\text { H } 4,90 \\
\text { Cl } 15,85 \\
\text { N } 12,59\end{array}$ & $\begin{array}{c}\text { C 59,33 } \\
\text { H 4,98 } \\
\text { Cl 15,92 } \\
\text { N } 12,58\end{array}$ & 71 \\
\hline 5в & $\mathrm{C}_{10} \mathrm{H}_{9} \mathrm{ClN}_{2} \mathrm{O}_{2}$ & $\begin{array}{c}86-88 / \\
85-87[10]\end{array}$ & $\begin{array}{c}3.90 \text { с., } 3 \mathrm{H} \\
4.76 \text { с., } 2 \mathrm{H} \\
7.10 \text { д, } 2 \mathrm{H}, 7.96 \text { д. } 2 \mathrm{H}, \\
\mathrm{J}_{\mathrm{HН}}=8 \text { Гц }\end{array}$ & $\begin{array}{l}\text { C } 53,48 \\
\text { H } 4,08 \\
\text { Cl } 15,70 \\
\text { N } 12,49\end{array}$ & $\begin{array}{l}\text { C } 53,47 \\
\text { H } 4,04 \\
\text { Cl } 15,78 \\
\text { N } 12,47\end{array}$ & 67 \\
\hline $5 \Gamma$ & $\mathrm{C}_{9} \mathrm{H}_{6} \mathrm{Cl}_{2} \mathrm{~N}_{2} \mathrm{O}$ & $\begin{array}{c}83-85 / \\
82-85[10]\end{array}$ & $\begin{array}{c}4.80 \text { с., } 2 \mathrm{H} \\
7.46 \text { д, } 2 \mathrm{H}, 7.98 \text { д. } 2 \mathrm{H}, \\
\mathrm{J}_{\mathrm{HН}}=8.8 \text { Гц }\end{array}$ & $\begin{array}{l}\text { C } 47,48 \\
\text { H } 2,28 \\
\text { Cl } 30,50 \\
\text { N } 12,29\end{array}$ & $\begin{array}{l}\text { C } 47,19 \\
\text { H } 2,64 \\
\text { Cl } 30,95 \\
\text { N } 12,23\end{array}$ & 73 \\
\hline 5д & $\mathrm{C}_{9} \mathrm{H}_{6} \mathrm{ClFN}_{2} \mathrm{O}$ & $\begin{array}{c}138-139 / 138- \\
140[10]\end{array}$ & $\begin{array}{c}4.80 \text { с., } 2 \mathrm{H} \\
7.86 \text { д, } 2 \mathrm{H}, 8.48 \text { д. } 2 \mathrm{H}, \\
\mathrm{J}_{\mathrm{Hн}}=9 \text { Гц }\end{array}$ & $\begin{array}{c}\text { C 50,95 } \\
\text { H 2,91 } \\
\text { Cl 16,76 } \\
\text { F 8,99 } \\
\text { N } 13,21 \\
\end{array}$ & $\begin{array}{c}\text { C 50,84 } \\
\text { H 2,84 } \\
\text { Cl 16,67 } \\
\text { F 8,94 } \\
\text { N } 13,18 \\
\end{array}$ & 68 \\
\hline $5 e$ & $\mathrm{C}_{9} \mathrm{H}_{6} \mathrm{ClBrN}_{2} \mathrm{O}$ & $105-108[10]$ & $\begin{array}{c}4.78 \text { с., } 2 \mathrm{H} \\
7.46 \text { д, } 2 \mathrm{H}, 7.96 \text { д. } 2 \mathrm{H}, \\
\mathrm{J}_{\mathrm{HН}}=9.1 \text { Гц }\end{array}$ & $\begin{array}{c}\text { C 39,63 } \\
\text { H 2,32 } \\
\text { Cl 12,99 } \\
\text { Br 29,32 } \\
\text { N } 10,28\end{array}$ & $\begin{array}{c}\text { C 39,53 } \\
\text { H 2,21 } \\
\text { Cl 12,96 } \\
\text { Br 29,21 } \\
\text { N 10,24 }\end{array}$ & 60 \\
\hline $5 \mathbf{c}$ & $\mathrm{C}_{9} \mathrm{H}_{6} \mathrm{ClN}_{3} \mathrm{O}_{3}$ & $\begin{array}{c}130-132 / 133- \\
135[11]\end{array}$ & $\begin{array}{c}4.82 \text { с., } 2 \mathrm{H} \\
8.36 \text { д, } 2 \mathrm{H}, 9.08 \text { д. } 2 \mathrm{H}, \\
\mathrm{J}_{\mathrm{Hн}}=9.1 \text { Гц }\end{array}$ & $\begin{array}{l}\text { C } 45,22 \\
\text { H } 2,50 \\
\text { Cl } 14,92 \\
\text { N } 17,60\end{array}$ & $\begin{array}{l}\text { C } 45,11 \\
\text { H } 2,52 \\
\text { Cl } 14,80 \\
\text { N } 17,54\end{array}$ & 73 \\
\hline $5 \%$ & $\mathrm{C}_{9} \mathrm{H}_{5} \mathrm{Cl}_{3} \mathrm{~N}_{2} \mathrm{O}$ & $\begin{array}{c}84-86 / \\
85-87[10]\end{array}$ & $\begin{array}{c}4.78 \text { с., } 2 \mathrm{H} \\
7.46 \text { д, } 2 \mathrm{H}, 7.96 \text { д. } 2 \mathrm{H}, \\
\mathrm{J}_{\mathrm{HН}}=9.1 \text { Гц }\end{array}$ & $\begin{array}{l}\text { C } 41,15 \\
\text { H } 1,96 \\
\text { Cl } 40,45 \\
\text { N } 10,61\end{array}$ & $\begin{array}{l}\text { C } 41,02 \\
\text { H } 1,91 \\
\text { Cl } 40,36 \\
\text { N } 10,63\end{array}$ & 70 \\
\hline 53 & $\mathrm{C}_{9} \mathrm{H}_{5} \mathrm{Cl}_{3} \mathrm{~N}_{2} \mathrm{O}$ & 116-118 & $\begin{array}{c}4.78 \text { с., } 2 \mathrm{H} \\
7.46 \text { д, } 2 \mathrm{H}, 7.96 \text { д. } 2 \mathrm{H}, \\
\mathrm{J}_{\mathrm{HН}}=9.1 \text { Гц }\end{array}$ & $\begin{array}{c}\text { C } 41,10 \\
\text { H } 1,98 \\
\text { Cl } 40,42 \\
\text { N } 10,64 \\
\end{array}$ & $\begin{array}{l}\text { C } 41,02 \\
\text { H } 1,91 \\
\text { Cl } 40,36 \\
\text { N } 10,63 \\
\end{array}$ & 65 \\
\hline $5 i$ & $\mathrm{C}_{9} \mathrm{H}_{6} \mathrm{ClBrN}_{2} \mathrm{O}$ & $\begin{array}{c}104-106 / 104- \\
107[11]\end{array}$ & $\begin{array}{c}4.78 \text { с., } 2 \mathrm{H} \\
7.46 \text { д, } 2 \mathrm{H}, 7.96 \text { д. } 2 \mathrm{H}, \\
\mathrm{J}_{\mathrm{HН}}=9.1 \text { Гц }\end{array}$ & $\begin{array}{c}\text { C } 39,66 \\
\text { H } 2,34 \\
\text { Cl } 12,98 \\
\text { Br 29,41 } \\
\text { N } 10,26 \\
\end{array}$ & $\begin{array}{c}\text { C 39,53 } \\
\text { H 2,21 } \\
\text { Cl 12,96 } \\
\text { Br 29,21 } \\
\text { N 10,24 }\end{array}$ & 56 \\
\hline $5 \kappa$ & $\mathrm{C}_{10} \mathrm{H}_{9} \mathrm{ClN}_{2} \mathrm{O}_{2}$ & $84-86$ & $\begin{array}{c}4.78 \text { с., } 2 \mathrm{H} \\
7.46 \text { д, } 2 \mathrm{H}, 7.96 \text { д. } 2 \mathrm{H}, \\
\mathrm{J}_{\mathrm{HН}}=9.1 \text { Гц }\end{array}$ & $\begin{array}{l}\text { C } 53,51 \\
\mathrm{H} 4,06 \\
\text { Cl } 15,72 \\
\text { N } 12,48\end{array}$ & $\begin{array}{c}\text { C } 53,47 \\
\mathrm{H} 4,04 \\
\text { Cl } 15,78 \\
\text { N } 12,47\end{array}$ & 64 \\
\hline 5л & $\mathrm{C}_{11} \mathrm{H}_{11} \mathrm{ClN}_{2} \mathrm{O}$ & $\begin{array}{c}120-123 / 120- \\
122[11]\end{array}$ & $\begin{array}{c}4.78 \text { с., } 2 \mathrm{H} \\
7.46 \text { д, } 2 \mathrm{H}, 7.96 \text { д. } 2 \mathrm{H}, \\
\mathrm{J}_{\mathrm{Hн}}=9.1 \text { Гц }\end{array}$ & $\begin{array}{l}\text { C } 59,39 \\
\mathrm{H} 4,96 \\
\mathrm{Cl} 15,98 \\
\mathrm{~N} 12,57\end{array}$ & $\begin{array}{l}\text { C } 59,33 \\
\text { H } 4,98 \\
\text { Cl } 15,92 \\
\text { N } 12,58 \\
\end{array}$ & 60 \\
\hline $5 \mathrm{M}$ & $\mathrm{C}_{7} \mathrm{H}_{5} \mathrm{ClN}_{2} \mathrm{O}_{2}$ & $\begin{array}{c}80-82 / \\
81-83[11]\end{array}$ & $\begin{array}{c}4.78 \text { с., } 2 \mathrm{H} \\
6.60-7.60 \text { м. } 3 \mathrm{H}\end{array}$ & $\begin{array}{c}\text { C } 45,65 \\
\text { H } 2,71 \\
\text { Cl } 19,32 \\
\text { N } 15,16\end{array}$ & $\begin{array}{l}\text { C } 45,55 \\
\text { H } 2,73 \\
\text { Cl } 19,21 \\
\text { N } 15,18\end{array}$ & 55 \\
\hline $5 \mathbf{H}$ & $\mathrm{C}_{7} \mathrm{H}_{5} \mathrm{ClN}_{2} \mathrm{OS}$ & $\begin{array}{c}78-80 / \\
77-79[11]\end{array}$ & $\begin{array}{c}4.78 \text { с., } 2 \mathrm{H} \\
7.40-7.60 \text { м., } 3 \mathrm{H}\end{array}$ & $\begin{array}{c}\text { C 41,96 } \\
\text { H 2,53 } \\
\text { Cl 17,75 } \\
\text { N } 13,99 \\
\text { S } 15,95\end{array}$ & $\begin{array}{c}\text { C 41,90 } \\
\text { H 2,51 } \\
\text { Cl 17,67 } \\
\text { N } 13,96 \\
\text { S } 15,98 \\
\end{array}$ & 68 \\
\hline
\end{tabular}

* вихід у розрахунку на вихідну карбонову кислоту 
До 0.2 моль гідразиду карбонової кислоти 3а-л додавали 250 мл толуену, осушеного за допомогою $\mathrm{P}_{2} \mathrm{O}_{5}$, за один прийом - 0,205 моль хлорацетилхлориду. Реакційну суміш нагрівали до кипіння, спостерігаючи виділення хлороводню. Нагрівання припиняли після закінчення виділення газу. Суміш охолоджували до кімнатної температури, осад, який утворився (речовини 4а-л), відфільтровували, висушували за $60^{\circ} \mathrm{C}$ до постійної маси. Виходи складали 75-98\%.

Загальна методика синтезу 2-арил-5хлорметил-1,3,4-оксадіазолів 5а-л. До 0,15 моль сполук 4а-л, одержаних на попередній стадії, додавали 0,3 моль $\mathrm{POCl}_{3}$ та нагрівали до кипіння, спостерігаючи виділення хлороводню. Реакцію проводили при перемішуванні за допомогою магнітної мішалки. Після закінчення виділення газу (приблизно 1,5-2 години) реакційну суміш продовжували нагрівати ще 15-20 хвилин, потім охолоджували до кімнатної температури. Для виділення продукту реакційну суміш невеликими порціями виливали на 0,5 кг льоду при постійному перемішуванні та розтиранні грудок, які утворювалися. Якщо лід танув, додавали необхідну його кількість для того, щоб суміш увесь час залишалась холодною. Осад, який утворювався, відфільтровували та промивали холодною водою до нейтральної реакції, висушували у вакуум-ексикаторі над $\mathrm{P}_{2} \mathrm{O}_{5}$. Одержували цільові речовини 5а-л у вигляді порошків кольору від світло-коричневого до коричневого. Виходи складали від 70 до 95\%.

Загальна методика синтезу 5-(2-фурил)-2хлорметил-1,3,4-оксадіазолів 5м-н. Метилові естери одержують згідно загальноприйнятої процедури з відповідних карбонових кислот і метилового спирту. В подальшому до розчину метилового естеру в метанолі додають гідразин-гідрат, далі процедуру продовжують так, як це описано вище для сполук 4а-л, 5а-л.

Висновки. В результаті проведених досліджень авторами було розроблено зручний препаративний метод одержання 5-арил(гетерил)-2-хлорметил-1,3,4оксадіазолів, який грунтується на циклізації ацильованих хлорацетилхлоридом гідразидів відповідних карбонових кислот. Метод дозволяе синтезувати препаративні кількості цільових сполук із високими виходами та не потребує очистки проміжних речовин. Він придатний для одержання як широкого кола 1,3,4-оксадіазолів з ароматичними замісниками, так i для синтезу 5-тієніл- та 5-фурил-2-хлорметил-1,3,4оксадіазолів. Будову всіх отриманих сполук підтверджено спектрами ЯМР ${ }^{1} \mathrm{H}$, а їх склад - елементним аналізом. Чистота одержаних продуктів за даними хромато-мас спектрометрії досягала 95\%.

Результати проведених досліджень можуть бути застосовані у синтетичній практиці, а одержані сполуки є перспективними для їх подальшої хімічної модифікації з метою одержання біологічно активних похідних.

Список літератури:

1. Savarino A. A historical sketch of the discovery and development of HIV-1 integrase inhibitors. Expert Opin Investig Drugs. 2006. V. 15, P. 1507-1522.

2. James A.N.D., Growcott J.W. Zibotentan. Drugs Future. 2009. V. 34, P. 624-633.

3. Mohammed I., Kummetha I.R., Singh G., Sharova N., Lichinchi G., Dang J., Stevenson M., Rana T.M. 1,2,3-Triazoles as Amide Bioisosteres: Discovery of a New Class of Potent HIV-1 Vif Antagonists. J. Med. Chem. 2016. V. 59. P. 7677-7682.

4. Patel K.D., Prajapati S.M., Panchal N.S., Patel H.D. Review of Synthesis of 1,3,4-Oxadiazole Derivatives. Synth. Commun. 2014. V. 44. P. 1859-1875.

5. Boström J., Hogner A., Llinàs A., Wellner E., Plowright A.T. Oxadiazoles in medicinal chemistry. J. Med. Chem. 2012. V. 55, P. 1817-1830.

6. Kudelko A., Wróblowska M. An efficient synthesis of conjugated 5-aryl-1,3,4-oxadiazoles from 3-heteroarylacrylohydrazides and acid chlorides. Tetrahedron Letters. 2014. V. 55, P. 3252-3254.

7. Mlostoń G., Obijalska, E.; Żurawik, A.; Heimgartner A. Efficient synthesis of tri- and difluoroacetyl hydrazides as useful building blocks for non-symmetrically substituted, fluoroalkylated 1,3,4-oxadiazoles. Chem. Heterocyclic. Compd. 2016. V. 52, P. 133-139.

8. Верещагин Л.И., Верхозина О.Н., Покатилов Ф.А., Кижняев В.Н. Синтез 2-замещенных 5-трифторметил-1,3,4-оксадиазолов. Журн. органич. химии. 2007. Т. 43. Вып. 10. С. 1577-1578.

9. Симурова Н.В., Майборода Е.И. Синтез моно- и дизамещенных 1,3,4-оксадиазолов. Химия гетероиикл. соединений. 2019. Т. 55(7). Р. 604-607.

10. Leal J.G., Sauer A.C., Mayer J.C.P., Stefanello S.T., Gonçalves D.F., Soares F.A.A., A. Iglesias B.A., Back D.F., Oscar E. D. Rodrigues O.E.D., Dornelles L. Synthesis and electrochemical and antioxidant properties of chalcogenocyanateoxadiazole and 5-heteroarylchalcogenomethyl-1H-tetrazole derivatives. New Journal of Chemistry. 2017. V. 41. P. 5875-5873.

11. Research Chemicals Building Blocks. URL: http://matrixcsientific.com/. 


\section{Simurova N.V., Popova I.V., Mayboroda O.I., Karmachov O.O. A CONVENIENT METHOD FOR THE PREPARATION OF 2-ARYL(HETERYL)-5-CHLOROMETHYL-1,3,4-OXADIASOLES}

The 1,3,4-oxadiazole molecule is of considerable interest due to a wide range of biological and pharmacological activities and has been generally recognized as a privileged structure in drug chemistry. The development of convenient methods for the production of substituted 1,3,4-oxadiazoles is an important area of research. Particularly interesting are derivatives of 1,3,4-oxadiazoles containing of the reactive chloromethyl group, which allows their further chemical modification.

This paper is devoted to the development of a convenient preparative method of obtaining 2-aryl/heteryl5-chloromethyl-1,3,4-oxadiazoles. A scheme is proposed in which aromatic and heterocyclic carboxylic acids are commercially available starting materials. The method is based on the preparation of carboxylic acid hydrazides, their subsequent acylation and cyclization of synthesized intermediates under the action of phosphorus trichloroxide (V).

The advantages of the method are the high yields of the targeted 1,3,4-oxadiazoles and the absence of the need to purify the intermediate compounds, which greatly simplifies the procedure, shortens the required time, saves the necessary reagents. The method is suitable for the preparation of both a wide range of 5-aryl-2-chloromethyl-1,3,4-oxadiazoles and some derivatives with heterocyclic substituents, in particular 5-thienyl (furyl)-2-chloromethyl-1,3,4- oxadiazoles.

The structure of all the compounds obtained was confirmed by $1 H$ NMR spectra and their composition by elemental analysis. The results of these studies can be applied in synthetic practice, and the obtained compounds containing the reactive chloromethyl group are promising building blocks for their further chemical modification in order to obtain biologically active derivatives, which may find use as drugs, insecticides.

Key words: synthesis, cyclization, hydrazide, chloroacetyl chloride, 1,3,4-oxadiazole, phosphoryl chloride. 